\title{
Religiosity and Determinants of Safe Sex in Iranian Non-Medical Men Students
}

\author{
Kambiz Karimzadeh Shirazi · Mohammad Ali Morowatisharifabad
}

Published online: 17 June 2008

(C) Blanton-Peale Institute 2008

\section{Erratum to: J Relig Health DOI 10.1007/s10943-008-9174-1}

In the above mentioned article, the name of the first author's university was left out. The affiliation should have read as follows:

Yasuj University of Medical Sciences and Health Services, School of Health, Department of Public Health, Imam Hossein/Ostandari Square, Damideh Health Center, Yasuj, Iran

The online version of the original article can be found under doi:10.1007/s10943-008-9174-1.

K. K. Shirazi $(\bowtie)$

School of Health, Department of Public Health, Imam Hossein/Ostandari Square, Damideh Health Center, Yasuj University of Medical Sciences and Health Services, Yasuj, Iran

e-mail: karimzadehshirazi@yahoo.com

M. A. Morowatisharifabad

Yazd Shahid Sadooghi University of Medical Sciences and Health Services, P.O. Box 887, Daneshjoo Blvd, Yazd, Iran

e-mail: morowaty@yahoo.com 